period warranting any definite conclusions; but they are offered because here in every case is a definite pathological condition found in the respiratory tract, where we would logically expect it as a sequel to the nasopharyngitis, a clear history of which was obtained either as an acute or subacute inflammation in every case. While the gross abnormalities of the nose were corrected, and the general condition improved as far as possible, this had no apparent effect on the asthmatic attacks, which, however, yielded readily to local treatment, with freedom from recurrence in proportion as we were able to control or cure the ethmoiditis.

\section{A CASE OF TRICHINOSIS.}

BY GEORGE G. SEARS, M.D., BOSTON.

M. D., an Italian laborer about twenty-four years old, was admitted to my wards in the City Hospital, December 6, 1900. Six days before entrance he was attacked with pains in the legs and arms and a slight diarrhea, which was soon followed by constipation. He felt feverish and chilly. Soon after the appearance of the first symptoms he noticed considerable swelling of his face. He was a well-developed and nourished man, whose puffy face and eyelids, combined with his pallor, suggested an acute nephritis. The skin was hot and dry. The forearms and legs were swollen, the result rather of a general increase in the size of the muscles than of any change in the skin, which was not edematous. There was tenderness along the outer sides of both tibiæ, as'well as in the muscles of the calves, thighs and forearms, though in the latter situation it was less marked. The heart was laterally enlarged, and later a soft systolic murmur developed over the pulmonary area. The liver and spleen were normal. The tongue was heavily coated. A blood count showed 16,200 leucocytes, of which $17 \frac{1}{2} \%$ were eosinophiles. Two days later the white cells numbered $9,500,13 \%$ being eosinophiles. The reds numbered 5,240,000, and contained $90 \%$ of hemoglobin. The urine was concentrated, but was not otherwise noteworthy.

December 10th. A well-marked urticarial eruption appeared over the trunk and thighs. The face is less puffy and the muscles less tender.

December 17th. The temperature, which reached $104^{\circ}$ as its highest point and closely simulated typhoid fever in its course, returned to normal by lysis two days ago. Swelling and tenderness of the muscles had gone. The cardiac area was enlarged and extended three fingers' breadth beyond the right sternal border, and on the left one-quarter inch beyond the mamillary line. No murmur was heard. The liver reached from the fifth space to an inch below the costal margin, but the spleen could not be felt. The white cells numbered 10,800 , and contained $31 \%$ eosinophiles.

White counts made on December 19th and 23d and on January 3, 1901, showed, respectively,
9,800 , with $39 \%$ of the eosinophiles ; 12,400, with $33 \%$, and in the last count $23 \%$ of the eosinophiles.

He improved steadily and was discharged January $3 \mathrm{~d}$. His muscles were still weak and flabby, but the heart had returned practically to within normal limits. A piece of the left gastrocnemius was removed on December 8 th and submitted to Dr. Mallory, who reported acute myositis with occasional degeneration of muscle fibres with infiltration with leucocytes. No trichinæ. Ten days later a larger piece was removed from the right gastrocnemius, in which trichinæ were so abundant that thirteen were seen in one microscopic field.

The preceding case is the twenty-fifth which has found its way into literature since the discovery at the Johns Hopkins Hospital of a marked eosinophilia in trichinosis. All have been reported by American observers, and all have confirmed the first observation, with the exception of a fatal case reported by Howard, in which no differential count was made ante-mortem. An increase in the number of eosinophilic cells has been found as early as the fifth day, the earliest date on which a count was made, and in a case reported by Stump they still composed $15 \%$ of the whole at the end of four months. The proportion has at times reached extraordinary heights, $60 \%$ being exceeded in several instances, while in a case reported by $K e r r$ it was over $80 \%$. It is noteworthy that the higher counts were made comparatively late in the disease, days or even several weeks after the initial symptoms, and even after the fever had gone down and general improvement had taken place in the patient, so that, while the migrations of successive crops produced by the parent worm in the intestine might account for the earlier variations, they do not seem to explain the large numbers which appear so late that reparative processes must have already begun. The severity of the disease seems to have no effect on the relative number of these cells, but it may influence the extent of the leucocytosis.

\section{Ahedital Bragregia.}

\section{RECENT PROGRESS IN OTOLOGY.}

BY PHILIP haMMOND, M.D., Boston.

\section{ANATOMY AND PHYSIOLOGY.}

Zimmermas ${ }^{1}$ advances the theory that sound vibrations are transmitted through the drum to the air of the middle ear, and thence directly to the labyrinth, without the assistance in any way of the ossicular chain. Spear ${ }^{2}$ states that in many cases the presence of the drum is an actual hindrance to hearing, and shows that the drum may be punctured with impunity. In the case of small open perforations, most excellent results are obtained in his hands by the use of a small disc of absorbent cotton placed over the opening. 